\title{
Theologie des Lebens bei Paulus und Johannes
}

Ein theologisch-konzeptioneller Vergleich des Zusammenhangs von Glaube und Leben auf dem Hintergrund ihrer Glaubenssummarien

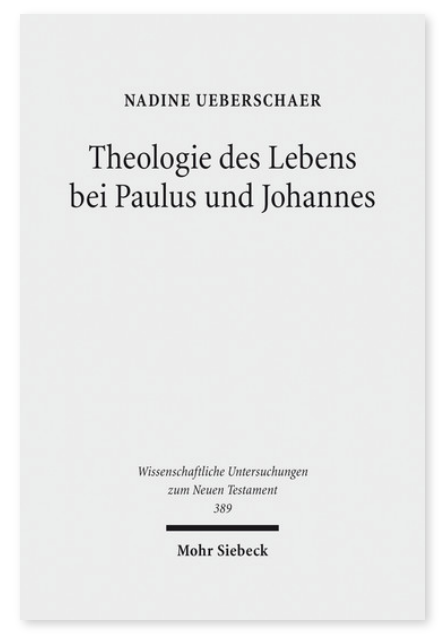

2017. XIII, 398 Seiten. WUNT I 389

ISBN 978-3-16-155674-6

DOI 10.1628/978-3-16-155674-6

eBook PDF 149,00€

ISBN 978-3-16-155041-6

Leinen $149,00 €$
Ausgehend von exegetischen Beobachtungen an zentralen Texten paulinischer Schriften und des Johannesevangeliums zeigt Nadine Ueberschaer auf, dass sowohl Paulus als auch Johannes auf der Grundlage frühchristlicher, vorpaulinischer Glaubenssummarien eine Theologie des Lebens entwickeln. Indem sie unabhängig voneinander das Kerygma von Jesu Tod und Auferstehung mit der Lebensbegrifflichkeit deutend fortschreiben, entstehen paulinische und johanneische Glaubenssummarien, in denen die soteriologische Gabe des Lebens für die Glaubenden entfaltet wird. In einem theologischkonzeptionellen Vergleich werden so erstmals umfassend Analogien des Lebensbegriffs der Paulusbriefe und des Johannesevangeliums herausgearbeitet.

Nadine Ueberschaer Geboren 1979; Studium der Ev. Theologie in München und Tübingen; Mitarbeiterin im Projekt »Bibel und Literatur (Westfälische Wilhelms-Universität Münster); 2010-14 wissenschaftliche Assistentin in Zürich; 2014-16 Vikariat; 2016 Abgabe der Dissertation; seit September 2016 Pfarrerin.
Jetzt bestellen:

https://mohrsiebeck.com/buch/theologie-des-lebens-bei-paulus-und-johannes-9783161556746?no_cache=1

order@mohrsiebeck.com

Telefon: +49 (0)7071-923-17

Telefax: +49(0)7071-51104 